\title{
Influence of GSTT1 and GSTP1 Polymorphisms on Type 2 Diabetes Mellitus and Diabetic Retinopathy Risk in the Chinese Population: A Case Control Study
}

\section{Xinqian Geng}

The Second People's Hospital of Yunnan Province

\section{Ling Zha}

The People's Hospital of Fengqing

\section{Taicheng Zhou}

The second People's Hospital of Yunnan Province

\section{Yixin Xiong}

The second People's Hospital of Yunnan Province

\section{Fan Xu}

The Second People's Hospital of Yunnan Province

\section{Bo Xu}

The second People's Hospital of Yunnan Province

\section{Feiying Wang}

The Second People's Hospital of Yunnan Province

\section{Xiaoling Wang}

The Second People's Hospital of Yunnan Province

\section{Ke Yang}

Shanghai Jiao Tong University Medical School Affiliated Ruijin Hospital Department of Cardiology Laboratory

Ying Yang ( $\square$ yangying2072@126.com )

The Second People's Hospital of Yunnan Province https://orcid.org/0000-0001-5753-7106

\section{Wenyu Tao}

The Second People's Hospital of Yunnan Province

\section{Yiping Li}

The Second People's Hospital of Yunnan Province

\section{Research}

Keywords: Glutathione S-Transferase, gene polymorphism, type 2 diabetes mellitus, diabetic retinopathy

Posted Date: August 5th, 2020

DOI: https://doi.org/10.21203/rs.3.rs-52199/v1 
License: () (1) This work is licensed under a Creative Commons Attribution 4.0 International License. Read Full License 


\section{Abstract}

Background: Studies have revealed the association of glutathione S-transferases (GSTM1 and GSTT1) deletion (null) polymorphism with the risks of developing type 2 diabetes mellitus (T2DM) and its complications. The present study aimed to investigate the relationship between GSTT1/ GSTP1 gene polymorphisms and the risks of T2DM and diabetic retinopathy (DR) in a Chinese population.

Methods: A total of 336 subjects with T2DM and a defined ophthalmologic status were recruited from the Second People's Hospital of Yunnan Province between June 2014 and October 2016. Seventy-two age-matched healthy controls were also enrolled. Physical examinations and laboratory tests were performed. The frequencies of GSTT1 and GSTP1 genotypes in all participants were determined by PCR and PCR-restriction fragment length polymorphisms (PCR-RFLP), respectively.

Results: Compared with healthy controls, the GSTT1-null genotype was significantly more common in diabetic patients with or without DR (all $P<0.05$ ). However, the frequency of the GSTP1 genotype (AA, GA, GG) was comparable between the two groups. Furthermore, neither the GSTP1 nor GSTT1 genetic polymorphism was associated with the development of DR. In the present study, the risk of developing T2DM was significantly higher in subjects carrying the combined heterozygous GSTP1 (AG) and null GSTT1 genotypes (OR=0.40, 95\% $\mathrm{Cl}=0.21-0.74, P=0.02)$.

Conclusions: The deletion of the GSTT1 genotype was associated with a higher risk of developing T2DM, whether alone or in combination with GSTP1, indicating that the null genotype of GSTT1 may serve as a potential biomarker for T2DM in the Chinese population, which is helpful for clinicians to make more effective risk-based decisions.

\section{Background}

Type 2 diabetes mellitus (T2DM) is an endocrine metabolic disorder that is characterized by impaired insulin action in target tissues and/or insulin secretion [1]. By 2040, 642 million people are expected to suffer from T2DM [2]. Notably, long-term hyperglycemia results in many complications, such as coronary artery disease, stroke, diabetic nephropathy, peripheral diabetic neuropathy, and diabetic retinopathy (DR), all of which carry high medical and socioeconomic costs [3]. T2DM is well recognized as a multifactorial disease determined by both genetic and environmental factors [3, 4]. Although genetic studies have demonstrated that some genetic markers are associated with T2DM susceptibility and provided new insights into diabetes pathogenesis, including $\beta$-cell function, adipocytokine signaling and cell cycle regulation, the genetic basis of T2DM and the mechanisms of the observed genetic associations of T2DM still need further investigation $[4,5,6,7]$.

Oxidative stress is an important factor in the development of diabetes and its complications $[8,9,10]$, and individuals with impaired antioxidant capacity were found to be at greater risk of T2DM $[11,12]$. Since the retina needs more oxygen than other tissues in the body, oxidative stress may also play a pivotal role in the etiology of DR [13]. Glutathione S-transferases (GSTs), a well-known multigenic superfamily of detoxification enzymes, can effectively modulate systemic oxidative stress levels in humans $[14,15]$. GSTM1 and GSTT1 are polymorphic, and the null genotypes (deletion of both alleles) are associated with reduced enzyme activity $[16,17,18]$. For GSTP1, there is a missense substitution from the A/G base at codon 105 in which isoleucine is replaced by 
valine (Ile105Val), resulting in an alteration of specific enzyme activity [19]. Several GST polymorphisms, especially GSTM1, GSTT1 and GSTP1, have been intensively studied in different diseases due to their potential effects on individual susceptibility to some environmentally induced diseases [20,21]. Recent studies have revealed the association of GSTM1/GSTT1 deletion (null) polymorphism with the risk of developing T2DM [14, $20,22,23,24,25]$. Moreover, the null genotypes of GSTM1/GSTT1 were also considered risk factors for various T2DM complications, including essential arterial hypertension, neuropathy, retinopathy, nephropathy, etc. [20, $23,26,27]$. However, few studies have focused on the relationships between GSTP1 single nucleotide polymorphism and the development of T2DM and its related complications, especially in the Chinese population. On the other hand, whether the GSTM1/GSTT1 polymorphisms are associated with risk of T2DM as well as DR is still controversial and inconsistent in the existing studies [20, 28, 29, 30].

Therefore, the present study aimed to investigate the relationships between GSTP1/GSTT1 genetic polymorphism and the risks of diabetes and DR in a Chinese population from Yunnan Province, a plateau area of Western China.

\section{Material And Methods}

\section{Study population}

In this cross-sectional study, a total of 336 subjects with T2DM and a defined ophthalmologic status were recruited from the Second People's Hospital of Yunnan Province between June 2014 and October 2016. Seventy-two age-matched healthy controls with no history of diabetes were also enrolled. The diagnosis of diabetes was in accordance with the 1999 World Health Organization criteria (fasting plasma glucose > $7.0 \mathrm{mmol} / \mathrm{L}, 2 \mathrm{~h}$ plasma glucose $>11.1 \mathrm{mmol} / \mathrm{L}$, or both) [31]. A complete ophthalmological examination (including corrected slit-lamp microscopic examination, funduscopic examination and fundus photography) was performed by a senior ophthalmologist following a standardized protocol at the Department of Ophthalmology, the Second People's Hospital of Yunnan Province. DR was defined and staged according to the proposed Clinical International Classification Systems. The T2DM group consisted of 124 subjects with proliferative diabetic retinopathy (PDR), 70 subjects with nonproliferative diabetic retinopathy (NPDR) and 142 diabetic subjects without clinical signs of diabetic retinopathy (NDR) [32].

\section{Ethical Principles}

The study was approved by the institutional review board of the Second People's Hospital of Yunnan Province and Yunnan University and was conducted in accordance with the principles of the Declaration of Helsinki. Written informed consent was provided by each participant prior to the study.

\section{Clinical Evaluation And Biochemical Assays}

All participants received an interviewer-administered questionnaire to collect general information regarding age, sex and history of diabetes and underwent a basic physical examination [e.g., weight, height, waist-to-hip ratio (WHR), systolic blood pressure and diastolic blood pressure] by trained nurses. Heparinized blood samples were 
collected after an overnight fast for at least $8 \mathrm{~h}$. Lipid profiles [including total cholesterol, triglycerides, highdensity lipoprotein (HDL), and low-density lipoprotein (LDL)], blood urea nitrogen (BUN), creatinine (CRE) and uric acid (UA) were measured on a Hitachi 7600 analyzer using an enzymatic assay. Glycated hemoglobin (HbA1c) was estimated by high-performance liquid chromatography using an analyzer (HLC-723 G7, Tosoh, Japan).

\section{Dna Extraction And Gst Genotyping Analysis}

DNA was extracted from the collected EDTA blood samples using a standard procedure of perchlorate/chloroform extraction [33]. Genotyping for the detection of the GSTT1 and GSTP1 genotypes was performed by PCR and PCR-restriction fragment length polymorphisms (PCR-RFLP), respectively. The albumin locus was used as an internal control to distinguish the null genotype of GSTT1 from the aborted PCRs. The primers used in the present study were as follows: GSTT1, 5'-TTC CTT ACT GGT CCT CAC ATC TC-3' (forward) and 5'-TCA CCG GAT CAT GGC CAG CA-3' (reverse); GSTP1, 5'-ACC CCA GGG CTC TAT GGG AA-3' (forward) and 5'-TGA GGG CAC AAG AAG CCC CT-3' (reverse); and Albumin, 5'-GCC CTC TGC TAA CAA GTC CTA C-3' (forward) and 5'-GCCCTAAAAAGAAAATCGCCA ATC-3' (reverse).

\section{Statistical analysis}

Data were expressed as the mean \pm standard deviation (SD) for normally distributed variables or as median (interquartile range $25-75 \%$ ) for variable with a skewed distribution. For continuous variables, differences between the healthy control group and T2DM group were evaluated using Student's t-test or Mann-Whitney U test. Comparisons among diabetic groups were evaluated by one-way ANOVA or the Kruskal-Wallis test as appropriate. For categorical variables, data were presented as $\mathrm{n}(\%)$, and comparisons between groups were analyzed by chi-square test. The relationships between GSTT1 and GSTP1 genotypes and the risks of T2DM and DR were assessed by the means of the odds ratio (OR) with $95 \%$ confidence interval $(\mathrm{Cl})$ limits calculated by logistic regression analysis. All tests were two-tailed, and values of $P<0.05$ were considered statistically significant. Statistics were performed with SPSS version 13.0 (SPSS, Inc., Chicago, IL, USA).

\section{Results}

\section{Characteristics of the study population}

The demographic and clinical characteristics of T2DM patients and healthy controls are illustrated in Table 1. Compared with healthy controls, diabetic patients tended to have a longer duration of diabetes, higher $\mathrm{BMI}$ and WHR (all $P<0.05$ ). In addition, HbA1c, total cholesterol, triglyceride, LDL-C, BUN and CRE were significantly higher in the T2DM diabetes group (all $P<0.05$ ). The proportions of men and women, age, SBP and DBP were comparable between the two groups. Among the 336 T2DM patients, 142 (42.26\%) had no signs of DR, 70 (20.83\%) had NPDR, and 124 (36.90\%) had PDR. DR was significantly associated with lower triglyceride levels but higher CRE (all $P<0.01$ ). 
Table 1

Characteristics of patients with T2DM with/without DR and healthy controls

\begin{tabular}{|c|c|c|c|c|c|}
\hline & NDR & NPDR & PDR & T2DM & Control \\
\hline Sample (n) & 142 & 70 & 124 & 336 & 72 \\
\hline Age (years) & $\begin{array}{l}54.40 \pm \\
14.20\end{array}$ & $\begin{array}{l}53.80 \pm \\
13.13\end{array}$ & $\begin{array}{l}57.20 \pm \\
15.43\end{array}$ & $52.20 \pm 10.31$ & $\begin{array}{l}55.11 \pm \\
11.23\end{array}$ \\
\hline Sex (male/female) & $52 / 58$ & $33 / 45$ & $54 / 51$ & $151 / 142$ & $53 / 47$ \\
\hline $\begin{array}{l}\text { Duration of diabetes } \\
\text { (months) }\end{array}$ & $\begin{array}{l}87.21 \pm \\
55.08\end{array}$ & $\begin{array}{l}104.85 \pm \\
65.02\end{array}$ & $\begin{array}{l}124.65 \pm \\
58.11\end{array}$ & $\begin{array}{l}92.65 \pm \\
73.26^{*}\end{array}$ & 0 \\
\hline BMI $\left(\mathrm{kg} / \mathrm{m}^{2}\right)$ & $24.56 \pm 3.37$ & $25.27 \pm 3.65$ & $25.02 \pm 3.34$ & $24.89 \pm 3.45^{*}$ & $22.41 \pm 2.12$ \\
\hline WHR & $0.92 \pm 0.07$ & $0.94 \pm 0.07$ & $0.93 \pm 0.06$ & $0.93 \pm 0.07 *$ & $0.82 \pm 0.01$ \\
\hline SBP (mmHg) & $\begin{array}{l}129.51 \pm \\
16.95\end{array}$ & $\begin{array}{l}134.63 \pm \\
19.89\end{array}$ & $\begin{array}{l}142.32 \pm \\
19.89\end{array}$ & $\begin{array}{l}134.67 \pm \\
19.36\end{array}$ & $\begin{array}{l}120.21 \pm \\
14.21\end{array}$ \\
\hline DBP (mmHg) & $\begin{array}{l}81.94 \pm \\
10.35\end{array}$ & $\begin{array}{l}81.99 \pm \\
12.28\end{array}$ & $\begin{array}{l}85.66 \pm \\
10.88\end{array}$ & $83.02 \pm 11.17$ & $79.30 \pm 9.24$ \\
\hline HbA1c(\%) & $9.08 \pm 2.45$ & $9.75 \pm 2.42$ & $9.44 \pm 2.21$ & $9.38 \pm 2.38 *$ & $5.52 \pm 0.43$ \\
\hline $\begin{array}{l}\text { Total cholesterol } \\
(\mathrm{mmol} / \mathrm{L})\end{array}$ & $4.79 \pm 1.29$ & $5.06 \pm 1.38$ & $5.34 \pm 1.64$ & $4.70 \pm 1.21^{*}$ & $3.41 \pm 1.21$ \\
\hline Triglyceride (mmol/L) & $3.26 \pm 3.33$ & $2.58 \pm 2.41 \dagger$ & $2.41 \pm 1.45 t$ & $3.52 \pm 2.32^{\star}$ & $1.61 \pm 0.32$ \\
\hline HDL-C (mmol/L) & $1.01 \pm 0.65$ & $0.98 \pm 0.24$ & $1.01 \pm 0.13$ & $1.01 \pm 0.46$ & $0.86 \pm 0.25$ \\
\hline LDL-C (mmol/L) & $2.44 \pm 0.92$ & $2.67 \pm 0.91$ & $2.72 \pm 0.93$ & $2.59 \pm 0.93^{*}$ & $2.18 \pm 0.52$ \\
\hline BUN (mmol/L) & $5.27 \pm 2.24$ & $5.71 \pm 2.25$ & $7.34 \pm 3.14 t$ & $5.84 \pm 0.81 *$ & $4.32 \pm 2.23$ \\
\hline UA (umol/L) & $\begin{array}{l}349.62 \pm \\
102.17\end{array}$ & $\begin{array}{l}354.39 \pm \\
105.94\end{array}$ & $\begin{array}{l}368.02 \pm \\
94.24\end{array}$ & $\begin{array}{l}356.43 \pm \\
102.34^{\star}\end{array}$ & $\begin{array}{l}307.60 \pm \\
26.11\end{array}$ \\
\hline CRE(umol/L) & $\begin{array}{l}71.64 \pm \\
26.29\end{array}$ & $\begin{array}{l}73.08 \pm \\
38.54 \uparrow\end{array}$ & $\begin{array}{l}103.85 \pm \\
76.32 \dagger\end{array}$ & $\begin{array}{l}84.47 \pm \\
55.57^{*}\end{array}$ & $67.96 \pm 6.04$ \\
\hline \multicolumn{6}{|c|}{$\begin{array}{l}\text { Data were expressed as mean } \pm \text { standard deviation }(\mathrm{SD}) .{ }^{*}, P \otimes 0.05 \text { compared with normal group. }+, P \otimes 0.01 \\
\text { compared with NDR group. }\end{array}$} \\
\hline \multicolumn{6}{|c|}{$\begin{array}{l}\text { T2DM, type } 2 \text { diabetes mellitus; DR, diabetic retinopathy; NDR, diabetic subjects without clinical signs of } \\
\text { diabetic retinopathy; NPDR, subjects with non-proliferative diabetic retinopathy; PDR, subjects with } \\
\text { proliferative diabetic retinopathy; BMI, body mass index; WHR, waist to hip ratio; SBP, systolic blood } \\
\text { pressure; DBP, diastolic blood pressure; HbA1c, glycated hemoglobin; HDL-C, high-density lipoprotein } \\
\text { cholesterol; LDL-C, low-density lipoprotein cholesterol; BUN, blood urea nitrogen; CRE, creatinine. }\end{array}$} \\
\hline
\end{tabular}

\section{The Frequency Distributions Of Gstp1 In T2dm And Controls}

Genotype distributions of the GSTP1 codon 105 variant in groups were in agreement with Hardy-Weinberg equilibrium (HWE) (Table 2, all $P>0.05$ ). However, HWE was not suitable for the GSTT1 variants because heterozygous individuals could not be distinguished from the homozygous wild type. The distributions of 
GSTP1 genetic polymorphisms among (1) patients with T2DM and healthy controls and (2) diabetic patients with and without DR are displayed in Table 3. The frequency of the GSTP1 genotypes was comparable between T2DM patients and controls, as well as diabetic patients with and without DR.

Table 2

HWE testing of genotype distributions of GSTP1 between T2DM patients with/without DR and healthy controls

\begin{tabular}{|c|c|c|c|c|c|c|}
\hline & & Freque & GSTP1 & & $x^{2}$ & $P$ \\
\hline & & AA & GA & GG & & \\
\hline NDR & Measured values & 62 & 15 & 8 & 5.35 & 0.07 \\
\hline & Predicted values & 56.83 & 25.35 & 2.83 & & \\
\hline NPDR & Measured values & 45 & 5 & 2 & 1.89 & 0.39 \\
\hline & Predicted values & 43.39 & 8.22 & 0.39 & & \\
\hline PDR & Measured values & 45 & 10 & 7 & 5.58 & 0.06 \\
\hline & Predicted values & 40.32 & 19.35 & 2.32 & & \\
\hline Control & Measured values & 47 & 13 & 2 & 0.33 & 0.85 \\
\hline & Predicted values & 46.17 & 14.67 & 1.17 & & \\
\hline
\end{tabular}

Table 3

Genotype distributions of GSTP1 between T2DM patients with/without DR and healthy controls Genotypes (1)

(2)

\begin{tabular}{|c|c|c|c|c|c|c|c|c|c|}
\hline & & Control & T2DM & $P$ & OR $(95 \% \mathrm{Cl})$ & NDR & DR & $P$ & OR $(95 \% \mathrm{Cl})$ \\
\hline & & No. (\%) & No. (\%) & & & No. (\%) & No. (\%) & & \\
\hline \multirow[t]{2}{*}{ a. } & AA & $47(75)$ & $152(76)$ & \multirow[t]{2}{*}{0.88} & \multirow{2}{*}{$\begin{array}{l}1.04(0.63- \\
1.73)\end{array}$} & $62(73)$ & $90(79)$ & \multirow[t]{2}{*}{0.32} & \multirow{2}{*}{$\begin{array}{l}1.29(0.78- \\
2.12)\end{array}$} \\
\hline & GAVGG & $15(25)$ & $47(24)$ & & & 23(27) & $24(21)$ & & \\
\hline \multirow[t]{2}{*}{ b. } & GA & $13(21)$ & $30(15)$ & \multirow[t]{2}{*}{0.27} & \multirow{2}{*}{$\begin{array}{l}0.93(0.81- \\
1.07)\end{array}$} & $15(18 \%)$ & 15(13) & \multirow[t]{2}{*}{0.38} & \multirow{2}{*}{$\begin{array}{l}0.95(0.84- \\
1.07)\end{array}$} \\
\hline & GG/AA & 49(79) & 169(85) & & & 70(82) & $99(87)$ & & \\
\hline \multirow[t]{2}{*}{ c. } & GG & 2(3) & $17(9)$ & \multirow[t]{2}{*}{0.16} & \multirow{2}{*}{$\begin{array}{l}1.06(0.99- \\
1.13)\end{array}$} & $8(9)$ & $9(8)$ & \multirow[t]{2}{*}{0.70} & \multirow{2}{*}{$\begin{array}{l}0.98(0.90- \\
1.07)\end{array}$} \\
\hline & GA/AA & $60(97)$ & 182(91) & & & 77(91) & $105(92)$ & & \\
\hline
\end{tabular}


For GSTT1, a significantly higher frequency of the GSTT1-null genotype was found in patients with T2DM compared with healthy controls $(49.41 \%$ vs. $34.72 \%, P=0.02)$. Moreover, the GSTT1-null genotype was significantly more frequent in diabetic patients with or without DR than in healthy controls (all $P<0.05$, Table 4). The frequency of the GSTT1-null genotype was similar among NDR, NPDR, and PDR.

Table 4

Genotype distributions of GSTT1 between T2DM patients with/without DR and healthy controls

\begin{tabular}{|c|c|c|c|c|c|c|}
\hline \multicolumn{2}{|c|}{ Group } & \multicolumn{2}{|c|}{ Genotype distributions $n(\%)$} & \multirow[t]{2}{*}{$x^{2}$} & \multirow[t]{2}{*}{$P$} & \multirow[t]{2}{*}{ OR $(95 \% \mathrm{Cl})$} \\
\hline & & Null & Present & & & \\
\hline \multirow[t]{2}{*}{ (1) } & $\mathrm{N}$ & $25(34.72)$ & $47(65.28)$ & 5.13 & 0.02 & $1.84(1.08-3.12)$ \\
\hline & T2DM & 166(49.41) & $170(50.60)$ & & & \\
\hline \multirow[t]{2}{*}{ (2) } & $\mathrm{N}$ & $25(34.72)$ & $47(65.28)$ & 4.51 & 0.03 & $1.88(1.05-3.38)$ \\
\hline & NDR & $71(50.00)$ & $71(50.00)$ & & & \\
\hline \multirow[t]{2}{*}{ (3) } & NDR & $71(50.00)$ & $71(50.00)$ & 0.61 & 0.43 & $0.80(0.45-1.4)$ \\
\hline & NPDR & $31(44.29)$ & $39(55.71)$ & & & \\
\hline \multirow[t]{2}{*}{ (4) } & NDR & $71(50.00)$ & $71(51.00)$ & 0.07 & 0.79 & $1.07(0.66-1.73)$ \\
\hline & PDR & $64(51.61)$ & $60(48.39)$ & & & \\
\hline \multirow[t]{2}{*}{ (5) } & NPDR & $31(44.29)$ & $39(55.71)$ & 0.96 & 0.33 & $1.34(0.75-2.42)$ \\
\hline & PDR & $64(51.61)$ & $60(48.39)$ & & & \\
\hline \multirow[t]{2}{*}{ (6) } & NDR & $71(50.00)$ & $71(51.00)$ & 0.04 & 0.85 & $0.96(0.62-1.48)$ \\
\hline & DR & $95(48.97)$ & $99(51.03)$ & & & \\
\hline
\end{tabular}

\section{Associations between the GSTP1/GSTT1 polymorphism and the risk of T2DM and DR}

The frequency distributions of the combination of GSTP1 and GSTT1 in healthy controls and in T2DM patients with or without DR are presented in Table 5. The combination of the GSTT1-null and GSTP1 (AG) genotype conferred the highest risk of developing T2DM (OR $=0.40,95 \% \mathrm{Cl} 0.21-0.74, P=0.02)$. However, the combination of the two genotypes (GSTT1 and GSTP1) showed no increased risk for developing DR in diabetic patients. 
Table 5

Combination of distributions of GSTP1 and GSTT1 in T2DM patients with/without DR and healthy controls

\begin{tabular}{|c|c|c|c|c|c|c|c|c|}
\hline \multirow[t]{2}{*}{ Genotypes } & \multicolumn{4}{|l|}{ (1) } & \multicolumn{3}{|l|}{ (2) } & \multirow[b]{2}{*}{$\begin{array}{l}\text { OR } \\
(95 \% \mathrm{Cl})\end{array}$} \\
\hline & $\begin{array}{l}\text { T2DM } \\
\text { No. (\%) }\end{array}$ & $\begin{array}{l}\text { Control } \\
\text { No. (\%) }\end{array}$ & $\mathbf{P}$ & $\begin{array}{l}\text { OR } \\
(95 \% \mathrm{Cl})\end{array}$ & $\begin{array}{l}\text { NDR } \\
\text { No. (\%) }\end{array}$ & $\begin{array}{l}\text { DR } \\
\text { No. (\%) }\end{array}$ & $\mathbf{P}$ & \\
\hline $\mathrm{T} 1(+) \mathrm{GG}$ & $6(3.22)$ & $1(2.00)$ & 0.55 & $\begin{array}{l}0.60(0.10- \\
3.70)\end{array}$ & $5(5.88)$ & $6(5.17)$ & 0.85 & $\begin{array}{l}0.95(0.55- \\
1.65)\end{array}$ \\
\hline $\mathrm{T} 1(+) \mathrm{AG}$ & 72(38.71) & $25(50.00)$ & 0.56 & $\begin{array}{l}1.14(0.74- \\
1.78)\end{array}$ & $23(27.06)$ & $41(35.34)$ & 0.18 & $\begin{array}{l}1.18(0.93- \\
1.51)\end{array}$ \\
\hline $\mathrm{T} 1(+) \mathrm{AA}$ & $12(6.45)$ & $7(14.00)$ & 0.16 & $\begin{array}{l}1.62(0.86- \\
3.05)\end{array}$ & $5(5.88)$ & $9(7.76)$ & 0.58 & $\begin{array}{l}1.13(0.75- \\
1.71)\end{array}$ \\
\hline $\mathrm{T} 1(-) \mathrm{GG}$ & $9(4.84)$ & $1(2.00)$ & 0.30 & $\begin{array}{l}0.41(0.06- \\
2.68)\end{array}$ & $3(3.53)$ & $5(4.31)$ & 0.29 & $\begin{array}{l}1.29(0.88- \\
1.89)\end{array}$ \\
\hline T1(-) AG & $75(40.32)$ & $10(20.00)$ & 0.02 & $\begin{array}{l}0.40(0.21- \\
0.74)\end{array}$ & $39(45.88)$ & $49(42.24)$ & 0.68 & $\begin{array}{l}0.95(0.75- \\
1.21)\end{array}$ \\
\hline T1(-) AA & $12(6.45)$ & $6(12.00)$ & 0.32 & $\begin{array}{l}1.45(0.72- \\
2.89)\end{array}$ & $10(11.76)$ & $6(5.17)$ & 0.10 & $\begin{array}{l}0.64(0.33- \\
1.21)\end{array}$ \\
\hline
\end{tabular}

\section{Discussion}

To our knowledge, this study is the first to explore the associations of GSTP1/GSTT1 genetic polymorphism with the risks of diabetes and DR in a Chinese population. In the present study, the GSTT1 null genotype was found to be an independent risk factor for the development of T2DM, whereas no significant association with DR $(P=0.65)$ was observed. GSTP1 also had no relationship with the development of T2DM and DR.

The GSTT1 gene is one of the most widely studied members of the GST family for its protective ability against oxidative stress in $\beta$-cells [34]. Currently, studies regarding the role of GSTT1 polymorphism and the risk of T2DM are inconclusive because of varying reports in different studies and in people of different ethnicities. On the one hand, some studies reported that there was no association of null GSTT1 with increasing risk for the development of T2DM [29, 34, 35, 36]. For example, although the frequency of both GSTT1-null and GSTM1-null genotypes in T2DM patients was significantly higher than that in the controls, the distribution of the GSTT1 null genotype was comparable between groups in southern Iran [29]. However, other studies reported the opposite results $[14,22,37]$. Pinheiro et al. reported that the GSTT1 polymorphism may play an important role in the pathogenesis of T2DM and complications associated with dyslipidemia in the Brazilian population [22]. Such discrepancies may result from small sample sizes, race and methodology. Considering the controversial results in this regard, a few meta-analyses were performed, and they revealed that both GSTT1 and GSTM1 conferred increased risk for T2DM $[38,39]$. Our study confirmed that the frequency of null GSTT1 was higher in T2DM patients than in controls, indicating an association of the GSTT1 null genotype and the risk of T2DM in the Chinese population. This result was consistent with the only study in Chinese people conducted by Wang et al. [14]. The GSTT1-null allele has been reported to be associated with both macrovascular and microvascular 
disease in T2DM patients, including diabetic nephropathy and retinopathy [20, 26, 39, 40,41]. In recent studies, it was demonstrated that the deletion polymorphism of GSTT1 could increase the risk for diabetic retinopathy in the Caucasian population [28, 42]. In contrast, both Dadbinpour et al. and Moasser et al. reported that there was no association between GSTT1 null genotypes and retinopathy in T2DM in the Iranian population [20, 36]. In our study, we found that the GSTT1-null genotype conferred a 1.8-fold increased risk of T2DM in subjects with and without DR compared to healthy controls (all $P<0.05$ ). However, the frequency of the GSTT1-null genotype was comparable between T2DM patients with and without DR, indicating that there was no significant relationship between GSTT1 null genotypes and DR in T2DM in the Chinese population. Larger prospective studies are needed to confirm our findings.

Considering that GST enzyme activity was significantly lower among individuals with the 105Val allele and that genetic polymorphisms reducing the activity of antioxidant enzymes could increase a person's susceptibility to some disease, it seems that the GSTP1 polymorphism may be associated with susceptibility to T2DM [43, 44]. However, studies regarding the association between GSTP1 polymorphism and the risk of T2DM yielded controversial results $[23,24,25,28,29,34,42,45,46,47]$. Some studies suggested that the GSTP1 polymorphism was associated with susceptibility to T2DM in Caucasian and African populations [23, 24, 25, 29, $42,46]$, whereas other studies did not observe a correlation between the GSTP1 polymorphism and T2DM in Caucasian and African individuals, as well as diabetes-related complications such as diabetic nephropathy in these populations $[26,34,35,47]$. In our study, the comparison of T2DM patients with healthy controls did not reveal a significant difference in the frequency of GSTP1 genotypes, which was in accordance with previous studies. These conflicting results may be attributed to the relatively small sample size and different ethnic backgrounds of the participants. Additionally, no association was observed between the GSTP1 polymorphism and susceptibility to DR in individuals with T2DM in the present study. Thus, exploring the relationship between GSTP1 polymorphism and the risk of DR in different populations is necessary.

For the combined effect of the GSTT1 and GSTP1 genotypes and the risk of progression of T2DM and DR, a significantly higher frequency of combined GSTT1 null genotype and GSTP1 heterozygous (AG) was observed in the whole T2DM group compared with the control group $(\mathrm{OR}=0.40,95 \% \mathrm{Cl}=0.21-0.74, P=0.02)(\mathrm{Table} 5)$. Our findings indicated that there may be an interaction or synergistic effect between each genotype, which may be more discriminating as risk factors for certain diseases.

\section{Conclusions}

In summary, the expression of GSTT1 was much higher in T2DM patients than in healthy controls, whereas the distribution of GSTT1 was comparable between T2DM patients with and without DR. There was no obvious association between GSTP1 polymorphisms and the risks for T2DM or DR. GSTT1 may serve as a candidate gene for T2DM in Chinese populations.

\section{Abbreviations}

T2DM

type 2 diabetes mellitus; DR:diabetic retinopathy; PCR-RFLP:PCR-restriction fragment length polymorphisms; GSTs:glutathione S-transferases; PDR:proliferative diabetic retinopathy; NPDR:nonproliferative diabetic retinopathy; NDR:diabetic subjects without clinical signs of diabetic retinopathy; WHR:waist-to-hip ratio; 
HDL:high-density lipoprotein; LDL:low density lipoprotein; BUN:blood urea nitrogen; CRE:creatinine; UA:uric acid; HbA1c:glycated hemoglobin; SD:standard deviation; OR:odds ratio; Cl:confidence interval; HWE:Hardy-Weinberg equilibrium.

\section{Declarations}

\section{Ethics approval and consent to participate}

The study was approved by the institutional review board of the Second People's Hospital of Yunnan Province and Yunnan University and was conducted in accordance with the principles of the Declaration of Helsinki.

\section{Consent for publication}

Not applicable.

\section{Availability of data and materials}

The datasets used in the present study are available from the corresponding author on reasonable request.

\section{Competing interests}

The authors declare that they have no competing interests.

\section{Funding}

This work was supported by grants from the Natural Science Foundation of China (No. 81760734 and No.31660313), the Natural Science Foundation of Yunnan Province (No.2017FA048), the fund of Diabetic Innovation Team (2019HC002), and the fund of Medical Leader in Yunnan Province (No. L-201609).

\section{Authors' contributions}

Yang Y, Tao WY and Li YP were responsible for the planning of the study and revising the manuscript for important intellectual content. Geng $X Q$ and $Z$ ha $L$ wrote the manuscript and analyzed and interpreted the data. Zhou TC, Xiong YX, Xu F, Xu B, Wang FY, Wang XL and Yang K performed the research. All authors reviewed the manuscript and approved the final draft.

\section{Acknowledgements}

Not applicable.

\section{References}

1. Tuomi T, Santoro N, Caprio S, Cai M, Weng J, Groop L. The many faces of diabetes: a disease with increasing heterogeneity. Lancet. 2014;383:1084-94.

2. Zimmet P, Alberti KG, Magliano DJ, Bennett PH. Diabetes mellitus statistics on prevalence and mortality: facts and fallacies. Nat Rev Endocrinol. 2016;12:616-22. 
3. Antonioli L, Blandizzi C, Csoka B, Pacher P, Hasko G. Adenosine signalling in diabetes mellituspathophysiology and therapeutic considerations. Nat Rev Endocrinol. 2015;11:228-41.

4. Bonnefond A, Froguel P, Vaxillaire M. The emerging genetics of type 2 diabetes. Trends Mol Med. 2010;16:407-16.

5. Steinthorsdottir V, Thorleifsson G, Sulem P, Helgason H, Grarup N, Sigurdsson A, et al. Identification of lowfrequency and rare sequence variants associated with elevated or reduced risk of type 2 diabetes. Nat Genet. 2014;46:294-8.

6. Morris AP, Voight BF, Teslovich TM, Ferreira T, Segre AV, Steinthorsdottir V, et al. Large-scale association analysis provides insights into the genetic architecture and pathophysiology of type 2 diabetes. Nat Genet. 2012;44:981-90.

7. Billings LK, Florez JC. The genetics of type 2 diabetes: what have we learned from GWAS? Ann N Y Acad Sci. 2010;1212:59-77.

8. Nowotny K, Jung T, Hohn A, Weber D, Grune T. Advanced glycation end products and oxidative stress in type 2 diabetes mellitus. Biomolecules. 2015;5:194-222.

9. Folli F, Corradi D, Fanti P, Davalli A, Paez A, Giaccari A, et al. The role of oxidative stress in the pathogenesis of type 2 diabetes mellitus micro- and macrovascular complications: avenues for a mechanistic-based therapeutic approach. Curr Diabetes Rev. 2011;7:313-24.

10. Giron MD, Salto R, Gonzalez Y, Giron JA, Nieto N, Periago JL, et al. Modulation of hepatic and intestinal glutathione S-transferases and other antioxidant enzymes by dietary lipids in streptozotocin diabetic rats. Chemosphere. 1999;38:3003-13.

11. Baynes JW, Thorpe SR. Role of oxidative stress in diabetic complications: a new perspective on an old paradigm. Diabetes. 1999;48:1-9.

12. Gallou G, Ruelland A, Legras B, Maugendre D, Allannic H, Cloarec L. Plasma malondialdehyde in type 1 and type 2 diabetic patients. Clin Chim Acta. 1993;214:227-34.

13. Kowluru RA, Kowluru V, Xiong Y, Ho YS. Overexpression of mitochondrial superoxide dismutase in mice protects the retina from diabetes-induced oxidative stress. Free Radic Biol Med. 2006;41:1191-6.

14. Wang G, Zhang L, Li Q. Genetic polymorphisms of GSTT1, GSTM1, and NQ01 genes and diabetes mellitus risk in Chinese population. Biochem Biophys Res Commun. 2006;341:310-3.

15. Hayes JD, Flanagan JU, Jowsey IR. Glutathione transferases. Annu Rev Pharmacol Toxicol. 2005;45:5188.

16. Binkova B, Chvatalova I, Lnenickova Z, Milcova A, Tulupova E, Farmer PB, et al. PAH-DNA adducts in environmentally exposed population in relation to metabolic and DNA repair gene polymorphisms. Mutat Res. 2007;620:49-61.

17. Pemble S, Schroeder KR, Spencer SR, Meyer DJ, Hallier E, Bolt HM, et al. Human glutathione S-transferase theta (GSTT1): cDNA cloning and the characterization of a genetic polymorphism. Biochem J. 1994;300(Pt 1):271-6.

18. Josephy PD. Genetic variations in human glutathione transferase enzymes: significance for pharmacology and toxicology. Hum Genomics Proteomics 2010; 2010: 876940.

19. Saadat M. Evaluation of glutathione S-transferase P1 (GSTP1) Ile105Val polymorphism and susceptibility to type 2 diabetes mellitus, a meta-analysis. EXCLI J. 2017;16:1188-97.

Page $12 / 14$ 
20. Dadbinpour A, Sheikhha MH, Darbouy M, Afkhami-Ardekani M. Investigating GSTT1 and GSTM1 null genotype as the risk factor of diabetes type 2 retinopathy. J Diabetes Metab Disord. 2013;12:48.

21. Katoh T, Yamano Y, Tsuji M, Watanabe M. Genetic polymorphisms of human cytosol glutathione Stransferases and prostate cancer. Pharmacogenomics. 2008;9:93-104.

22. Pinheiro DS, Rocha Filho CR, Mundim CA, Junior Pde M, Ulhoa CJ, Reis AA, et al. Evaluation of glutathione S-transferase GSTM1 and GSTT1 deletion polymorphisms on type-2 diabetes mellitus risk. PLoS One. 2013;8:e76262.

23. Stoian A, Banescu C, Balasa RI, Motataianu A, Stoian M, Moldovan VG, et al. Influence of GSTM1, GSTT1, and GSTP1 Polymorphisms on Type 2 Diabetes Mellitus and Diabetic Sensorimotor Peripheral Neuropathy Risk. Dis Markers 2015; 2015: 638693.

24. Mastana SS, Kaur A, Hale R, Lindley MR. Influence of glutathione S-transferase polymorphisms (GSTT1, GSTM1, GSTP1) on type-2 diabetes mellitus (T2D) risk in an endogamous population from north India. Mol Biol Rep. 2013;40:7103-10.

25. Rao DK, Shaik NA, Imran A, Murthy DK, Ganti E, Chinta C, et al. Variations in the GST activity are associated with single and combinations of GST genotypes in both male and female diabetic patients. Mol Biol Rep. 2014;41:841-8.

26. Orlewski J, Orlewska E. Effects of genetic polymorphisms of glutathione S-transferase genes (GSTM1, GSTT1, GSTP1) on the risk of diabetic nephropathy: a meta-analysis. Pol Arch Med Wewn. 2015;125:64958.

27. Petrovic D, Peterlin B. GSTM1-null and GSTT1-null genotypes are associated with essential arterial hypertension in patients with type 2 diabetes. Clin Biochem. 2014;47:574-7.

28. Cilensek I, Mankoc S, Petrovic MG, Petrovic D. GSTT1 null genotype is a risk factor for diabetic retinopathy in Caucasians with type 2 diabetes, whereas GSTM1 null genotype might confer protection against retinopathy. Dis Markers. 2012;32:93-9.

29. Bid HK, Konwar R, Saxena M, Chaudhari P, Agrawal CG, Banerjee M. Association of glutathione Stransferase (GSTM1, T1 and P1) gene polymorphisms with type 2 diabetes mellitus in north Indian population. J Postgrad Med. 2010;56:176-81.

30. Datta SK, Kumar V, Pathak R, Tripathi AK, Ahmed RS, Kalra OP, et al. Association of glutathione Stransferase M1 and T1 gene polymorphism with oxidative stress in diabetic and nondiabetic chronic kidney disease. Ren Fail. 2010;32:1189-95.

31. Alberti KG, Zimmet PZ. Definition, diagnosis and classification of diabetes mellitus and its complications. Part 1: diagnosis and classification of diabetes mellitus provisional report of a WHO consultation. Diabet Med. 1998;15:539-53.

32. Wilkinson CP, Ferris FL 3rd, Klein RE, Lee PP, Agardh CD, Davis M, et al. Proposed international clinical diabetic retinopathy and diabetic macular edema disease severity scales. Ophthalmology. 2003;110:167782.

33. Gonul N, Kadioglu E, Kocabas NA, Ozkaya M, Karakaya AE, Karahalil B. The role of GSTM1, GSTT1, GSTP1, and OGG1 polymorphisms in type 2 diabetes mellitus risk: a case-control study in a Turkish population. Gene. 2012;505:121-7. 
34. Yalin S, Hatungil R, Tamer L, Ates NA, Dogruer N, Yildirim H, et al. Glutathione S-transferase gene polymorphisms in Turkish patients with diabetes mellitus. Cell Biochem Funct. 2007;25:509-13.

35. Moasser E, Kazemi-Nezhad SR, Saadat M, Azarpira N. Study of the association between glutathione Stransferase (GSTM1, GSTT1, GSTP1) polymorphisms with type II diabetes mellitus in southern of Iran. Mol Biol Rep. 2012;39:10187-92.

36. Moasser E, Azarpira N, Shirazi B, Saadat M, Geramizadeh B. Genetic polymorphisms of glutathione-stransferase M1 and T1 genes with risk of diabetic retinopathy in Iranian population. Iran J Basic Med Sci. 2014;17:351-6.

37. Hori M, Oniki K, Ueda K, Goto S, Mihara S, Marubayashi T, et al. Combined glutathione S-transferase T1 and M1 positive genotypes afford protection against type 2 diabetes in Japanese. Pharmacogenomics. 2007;8:1307-14.

38. Zhang J, Liu H, Yan H, Huang G, Wang B. Null genotypes of GSTM1 and GSTT1 contribute to increased risk of diabetes mellitus: a meta-analysis. Gene. 2013;518:405-11.

39. Nath S, Das S, Bhowmik A, Ghosh SK, Choudhury Y. The GSTM1 and GSTT1 Null Genotypes Increase the Risk for Type 2 Diabetes Mellitus and the Subsequent Development of Diabetic Complications: A Metaanalysis. Curr Diabetes Rev. 2019;15:31-43.

40. Doney AS, Lee S, Leese GP, Morris AD, Palmer CN. Increased cardiovascular morbidity and mortality in type 2 diabetes is associated with the glutathione $S$ transferase theta-null genotype: a Go-DARTS study. Circulation. 2005;111:2927-34.

41. Sharif S, Maqsood M, Naz S, Manzoor F, Shah Jahan M, Farasat T. Expression of Gstt1 in Type 2 Diabetic Retinopathy Patients. Crit Rev Eukaryot Gene Expr. 2019;29:47-50.

42. Zaki MA, Moghazy TF, El-Deeb MMK, Mohamed AH, Mohamed NAA. Glutathione S-transferase M1, T1 and $\mathrm{P} 1$ gene polymorphisms and the risk of developing type 2 diabetes mellitus in Egyptian diabetic patients with and without diabetic vascular complications. Alexandria Journal of Medicine. 2015;51:73-82.

43. Makuc J, Petrovic D. A review of oxidative stress related genes and new antioxidant therapy in diabetic nephropathy. Cardiovasc Hematol Agents Med Chem. 2011;9:253-61.

44. Watson MA, Stewart RK, Smith GB, Massey TE, Bell DA. Human glutathione S-transferase P1 polymorphisms: relationship to lung tissue enzyme activity and population frequency distribution. Carcinogenesis. 1998;19:275-80.

45. Aw Ahmed F, Al-bachary S. H. Genetic Polymorphism of Glutathione-S-Transferase Gene (GSTP1) in Type 2 Diabetes Mellitus Patients in Basra Province/Iraq. International Journal of Sciences. 2017;3:1-7.

46. Mergani A, Mansour AA, Askar T, Zahran RN, Mustafa AM, Mohammed MA, et al. Glutathione S-Transferase Pi-lle 105 Val Polymorphism and Susceptibility to T2DM in Population from Turabah Region of Saudi Arabia. Biochem Genet. 2016;54:544-51.

47. Amer MA, Ghattas MH, Abo-Elmatty DM, Abou-El-Ela SH. Evaluation of glutathione S-transferase P1 genetic variants affecting type-2 diabetes susceptibility and glycemic control. Arch Med Sci. 2012;8:631-6. 